\title{
Overbilling and Informed Financial Consent - A Contractual Solution
}

Barak D. Richman, J.D., Ph.D., Mark A. Hall, J.D., and Kevin A. Schulman, M.D.

$\circlearrowleft$ S. hospitals and physicians have been known to charge uninsured patients and patients receiving care outside their healthplan networks an average of 2.5 times what most health insurers pay and more than 3 times their actual costs. ${ }^{1}$ Controversy over list prices triggered more than 120 lawsuits in 2004 and 2005, ${ }^{2}$ and the debate has found new relevance with increased calls in Congress for pricing transparency and the requirement in the Affordable Care Act (ACA) that nonprofit hospitals publicize their discounting policies for uninsured patients. The theory of implied contracts, a foundation in most first-year courses in contract law, offers a useful legal and ethical mechanism for handling these troubling problems in health care billing.

A staple law-school hypothetical illustrates the usual function of implied contracts: a physician encounters an unconscious stranger in the street who requires immediate medical attention. The physician promptly gives the stranger the requisite emergency care and later submits a bill for her services. Is she entitled to payment?

According to elementary contract principles, she is. Had the stranger been conscious and able to negotiate a contract before he required medical attention, he clearly would have consented to purchase the medical services. When parties are unable to negotiate - because of insufficient time or the inability to communicate, for example the law imputes an "implied contract," creating a legal obligation that mimics one created by mutual assent. ${ }^{3}$

This legal argument is usually invoked to enforce payment for medical services to which patients cannot expressly consent, but the logic of implied contracts works both ways: just as the law imputes an obligation to pay, it similarly imputes a price - that to which the patient and provider would have agreed. The doctrine thus limits the amount that providers can reasonably expect to receive to the prevailing market price. Accordingly, an impliedcontracts approach informs the way the law should handle accusations that providers use "list prices" to overcharge patients.

In a profession that places a high premium on informed consent, there are several reasons why providers do not obtain meaningful "informed financial consent" from patients before entering into financial agreements. Long-standing professional norms prevent discussion of fees before a physician cares for the sick, and enormous accounting complexity causes both providers and patients to lack the capacity to negotiate and assent to a bill. But the profession's failure to insist on informed financial consent has both triggered sharp criticism and fueled untamed health care prices, necessitating a better approach to assigning prices in contracts for health care services.

There are at least four mecha- nisms that can help solve the problem of excessive list-price billing. The first, which could be labeled a "market-based approach," is to require greater disclosure of providers' prices. Policy scholars have argued that greater billing transparency would enhance price competition among providers, and calls for more public reporting of average or list charges are gaining momentum. Although such aggregated reporting does little to help patients understand their financial options at the bedside, it offers the hope that greater transparency will bring list prices down to competitive levels.

A second approach, which appeals to professionalism, emphasizes that physicians and perhaps hospitals owe fiduciary duties to their patients. Medical ethics has traditionally separated the delivery of care from ordinary marketplace mores and profit-maximizing pricing. Building on this tradition, professional ethics could require providers to set prices that explicitly consider the interests of their patients as consumers with limited resources. Australia's medical profession has assumed this fiduciary role. In response to growing concern that providers were charging patients with private insurance 50 to $100 \%$ more than those covered only by the government, Australian doctors committed to telling patients in advance (when possible) how much they would pay out of pocket for a chosen course of treatment. ${ }^{4}$ As a result, more than half of privately insured Austra- 
lian patients with planned hospital admissions in 2007 gave financial consent to prices their providers specified in advance. ${ }^{5}$

A third approach is price regulation. Section 9007 of the ACA, for example, recognizes that list prices frequently do not reflect market forces and thus requires tax-exempt hospitals to collect from low-income uninsured patients "not more than the amounts generally billed to individuals who have insurance." Some state laws use similar mechanisms but with alternative benchmarks. A California law, passed in 2006, caps charges for the uninsured on the basis of Medicare rates, and a 2008 Illinois law links such caps to the cost of care. These regulatory approaches are consistent with a more broadly held belief that price regulation is necessary to correct certain market failures in health care, but they offer solutions only to uninsured patients in nonprofit hospitals and do not address the larger problems of billing for out-of-network care.

A fourth approach - the simplest and most preferable one, in our view - follows a logic akin to that of implied contracts. An implied-contracts approach would obligate a patient to pay whatever amount a prudent patient and provider would have agreed to, given appropriate time and information. The best proxy for informed bargaining is what similarly situated consumers and providers actually bargain for namely, the rates negotiated between providers and private insurers. After all, insurers are purchasers that possess sufficient information and options to negotiate market rates. Another use- ful proxy might be Medicare reimbursement rates, because those rates - offered by the government and accepted by providers, who are permitted to refuse also approximate the lower end of the range of prices that a reasonably informed negotiation would produce.

An implied-contracts approach prevents overbilling of both uninsured patients and patients who receive care outside negotiated networks. It also offers a method for defining widespread and intentionally ambiguous price terms found in the fine print of contracts that litter the health care marketplace, such as "usual" or "customary" prices. The law frequently fills in the gaps in ambiguous or incomplete contracts, not only when negotiations are impossible (as when an unconscious patient requires emergency care) but also when parties, for whatever reason, fail to produce fully specified contracts.

It is U.S. medicine's discomfort with discussing prices and, it must be said, the financial advantages of doing business this way - that makes so many medical contracts incomplete. Yet the law permits only what similarly situated parties would have agreed to if negotiations had been complete, not what providers say is their individual custom. Contractual incompleteness gives neither providers nor patients a general license to fill in the contractual gaps however they like after medical services are provided; instead, it enforces the contract that both parties would have created themselves if time and capacity had permitted.

It is time to revisit some of the billing practices that have brought us to a state of financial crisis in health care, and the decoupling of the relationship between price and service is among the health care market's biggest problems. Establishing informed financial consent as an essential element of medical practice would both fulfill the profession's ethical commitment to patient autonomy and provide a much-needed market-based counterforce to price escalation. But until that happens, the doctrine of implied contracts can and should be used to curtail some of the most abusive billing practices.

Disclosure forms provided by the authors are available with the full text of this article at NEJM.org.

From Duke University School of Law (B.D.R.), the Health Sector Management Program, Fuqua School of Business, Duke University (B.D.R., K.A.S.), and Duke Clinical Research Institute and Department of Medicine, Duke University School of Medicine (K.A.S.) - all in Durham, NC; and Wake Forest University School of Law, the Translational Science Institute, and Department of Social Sciences and Health Policy, Division of Public Health Sciences, Wake Forest University School of Medicine - all in Winston-Salem, NC (M.A.H.).

1. Anderson G. From 'soak the rich' to 'soak the poor': recent trends on hospital pricing. Health Aff (Millwood) 2007;26:780-9.

2. Witten JA. NFP litigation update: early decisions by federal courts favor hospitals. Bloomberg BNA Health Law Rep 2005; 14:7983.

3. Posner R. Economic analysis of law. 6th ed. New York: Aspen, 2003.

4. Informed financial consent: your right to know. Sydney: Australian Government Private Health Insurance Ombudsman (http://www .phio.org.au/facts-and-advice/informedfinancial-consent.aspx).

5. Public and private hospitals: research report. Melbourne, VIC: Australian Government Productivity Commission (http://www.pc .gov.au/projects/study/hospitals/report).

DOI: 10.1056/NEJMp1205225

Copyright () 2012 Massachusetts Medical Society. 